九州大学学術情報リポジトリ

Kyushu University Institutional Repository

\title{
Variation of Pollen Tube Behavior and Seed Set in Self-pollination of Lilium longiflorum Thunb.
}

Sakazono, Satomi

Laboratory of Horticultural Science, Division of Agricultural Botany, Department of Plant Resources, Graduate School of Bioresource and Bioenvironmental Sciences, Kyushu University

Hiramatsu, Michikazu

Laboratory of Horticultural Science, Division of Agricultural Botany, Department of Plant Resources, Graduate School of Bioresource and Bioenvironmental Sciences, Kyushu University

Okubo, Hiroshi

Laboratory of Horticultural Science, Division of Agricultural Botany, Department of Plant Resources, Graduate School of Bioresource and Bioenvironmental Sciences, Kyushu University

https://doi.org/10.5109/14034

出版情報：九州大学大学院農学研究院紀要. 54 (1)，pp.37-40，2009-02-27. Faculty of Agriculture， Kyushu University

バージョン :

権利関係 : 


\title{
Variation of Pollen Tube Behavior and Seed Set in Self-pollination of Lilium longiflorum Thunb.
}

\author{
Satomi SAKAZONO ${ }^{1 *}$, Michikazu HIRAMATSU \\ and Hiroshi OKUBO
}

\author{
Laboratory of Horticultural Science, Division of Agricultural Botany, Department of Plant Resources, \\ Faculty of Agriculture, Kyushu University, Fukuoka 812-8581, Japan \\ (Received November 14, 2008 and accepted December 5, 2008)
}

\begin{abstract}
Quantitative variation in seed set following artificial self-pollination has been recently demonstrated in Lilium longiflorum. Pollen tube behavior and seed set in self-pollination in the species were investigated to clarify whether the variation is caused by self-incompatibility or early-acting inbreeding depression. The self pollen tubes were arrested in the style of the individuals that failed to set selfed seeds, and total number of pollen tubes observed at the base of the style tended to correspond to that of obtained selfed seeds. It indicates that decrease of selfed seed number in L. longiflorum is caused by self-incompatibility but not by early-acting inbreeding depression.
\end{abstract}

\section{INTRODUCTION}

Self-incompatibility is a self-recognition and rejection mechanism controlled by S-allele to prevent selffertilization (de Nettancourt, 1977; Hiscock and Mclnnis, 2003), while early-acting inbreeding depression results in postzygotic seed abortion and reduction due to homozygote for deleterious recessive alleles (Charlesworth and Charlesworth, 1987; Harder and Barrett, 2006). Since the both fail to set seeds in self-pollination, these two mechanisms have been often confounded. A phenomenon to reduce selfed seed number has been determined whether it is resulted from self-incompatibility or earlyacting inbreeding depression in some species. Reduction in seed set in self-pollination of Eichhornia paniculata (Manicacci and Barrett, 1996) and Pseudowintera axillaris (Sage and Sampson, 2003) was due to self-incompatibility rather than inbreeding depression. On the other hand, it is suggested in Medicago sativa (Brink and Cooper, 1939), Leavenworthia (Lloyd, 1968) and Erythronium grandiflorum (Rigney, 1995) that the reduced seed numbers in self-pollination may be an expression of inbreeding depression during embryo development. Distinguishing self-incompatibility from early-acting inbreeding depression is difficult, but observation of self pollen tube behaviors is considered to be one of the methods to distinguish them because earlyacting inbreeding depression acts after fertilization, while self-incompatibility mainly acts before fertilization.

It is recently demonstrated that Lilium longiflorum Thunb. shows quantitative variation of selfed seed setting among individuals in natural populations (Sakazono et al., 2008). Incompatible (self) pollen tubes are arrested in the style and fertilization is failed in $L$. longiflorum regarded as a self-incompatible species

\footnotetext{
1 Laboratory of Horticultural Science, Division of Agricultural Botany, Department of Plant Resources, Graduate School of Bioresource and Bioenvironmental Sciences, Kyushu University

* Corresponding author (E-mail: sakazono@agr.kyushu-u.ac.jp)
}

(Ascher and Peloquin, 1968; Li and Niimi, 1995). Self pollen tube behavior was, however, examined only in a few cultivars of the species, and it has not been observed for individuals from natural populations. To clarify whether the factor causing quantitative variation of selfed seed set in L. longiflorum is due to self-incompatibility or to early-acting inbreeding depression, we investigated pollen tube behavior and seed set following artificial selfpollination.

\section{MATERIALS AND METHODS}

\section{Plant materials}

Lilium longiflorum seedlings were established from more than 20 capsules each collected from six natural populations (Table 1) and were grown in a greenhouse without heating at Kyushu University. Sakazono et al. (2008) examined the variation of the degree of selfincompatibility in L. longiflorum individuals from 18 natural populations and divided them into four classes, selfincompatibility, predominant self-incompatibility, weak self-incompatibility and self-compatibility by the result of selfed seed production. The population which is dom-

Table 1. Lilium longiflorum populations examined in this study

\begin{tabular}{cll}
\hline $\begin{array}{c}\text { Population } \\
\text { abbreviation }\end{array}$ & \multicolumn{1}{c}{ Locality } & $\begin{array}{c}\text { Compatibility } \\
\text { status of } \\
\text { population }\end{array}$ \\
\hline AM & Amamioshima island, Ryukyu Arc. & SC \\
TO & Tokunoshima island, Ryukyu Arc. & SC \\
YR & Yoronto island, Ryukyu Arc. & Mixed \\
IK & Ikemajima island, Ryukyu Arc. & Mixed \\
IS & Ishigakijima island, Ryukyu Arc. & Mixed \\
IR & Iriomotejima island, Ryukyu Arc. & Mixed \\
\hline
\end{tabular}

${ }^{\mathrm{z}} \mathrm{SC}$ indicates a population which is dominated by self-compatible and weaky self-incompatible individuals and Mixed indicates a population which is dominated by predominant self-incompatible and self-incompatible individuals (Sakazono et al., 2008). 
inated by self-compatible and weakly self-incompatible individuals is defined as SC population, and that dominated by self-incompatible and predominant self-incompatible individuals as mixed population. Two SC populations in Amamioshima Island (AM) and Tokunoshima Island (TO) and four mixed populations in Yoronto Island (YR), Ikemajima Island (IK), Ishigakijima Island (IS) and Iriomotejima Island (IR) were selected in this study. Proportion of self-compatible and weakly selfincompatible individuals in the populations varies among populations (AM; $60.7 \%$ and $28.6 \%$, TO; $31.8 \%$ and $40.9 \%$, YR; $18.9 \%$ and $21.6 \%$, IK; $0 \%$ and $11.1 \%$, IS; $0 \%$ and $3.3 \%$, IR; $2.1 \%$ and $8.5 \%$ respectively, Sakazono et al., 2008).

\section{Selfed seed production and observation of self pollen tube elongation}

Stigmatic self pollination was conducted on one flower per individual three days after anthesis in the greenhouse from middle May to early July 2006, and styles with stigma were collected $120 \mathrm{hrs}$ after the pollination. The styles were fixed in FAA (Ethyl alcohol 70\% : Formaldehyde : Acetic acid $=90: 5: 5$ ) and stored at room temperature until observation. They were washed in water, followed by softening for 24 to $25 \mathrm{hrs}$ in $1 \mathrm{~N}$ $\mathrm{NaOH}$ solution at $25^{\circ} \mathrm{C}$ and then washed with distilled water. Pollen tubes in the softened styles were stained for five to six hrs with $0.1 \%$ aniline blue and observed with fluorescence microscopy (Nikon E800). Number of individuals in each population used for the observation of pollen tube elongation was four to 10 (Table 2). Ovaries were kept on the plants after collecting styles, and enlarged capsules were collected about 60 days after pollination. Capsules that contained at least one mature seed with complete embryo and endosperm were regarded as successfully set, and proportion of capsule set and total seed number were investigated.

Cut-style self pollination was also conducted on one flower per self-incompatible individuals from four populations (YR, IK, IS and IR) in the greenhouse from late May to early July 2006. For cut-style pollination, styles were cut off at one $\mathrm{cm}$ above the ovary followed by about three mm longitudinal slitting in the remaining style. The style was covered with aluminum foil after being filled by self pollen into the slit. Total seed number was

Table 2. Number of individuals to selfed seed set in L. longiflorum

\begin{tabular}{|c|c|c|c|c|c|}
\hline \multirow[t]{2}{*}{ Population $^{2}$} & \multirow{2}{*}{$\begin{array}{c}\text { Number of } \\
\text { individuals } \\
\text { examined }\end{array}$} & \multicolumn{4}{|c|}{$\begin{array}{c}\text { Number of individuals contained } \\
\text { each selfed seed number }\end{array}$} \\
\hline & & 0 & $<10$ & $10-100$ & $100<$ \\
\hline $\mathrm{AM}$ & 4 & 0 & 0 & 2 & 2 \\
\hline TO & 6 & 0 & 1 & 2 & 3 \\
\hline YR & 7 & 3 & 1 & 2 & 1 \\
\hline IK & 5 & 4 & 0 & 0 & 1 \\
\hline IS & 8 & 8 & 0 & 0 & 0 \\
\hline IR & 10 & 9 & 0 & 0 & 1 \\
\hline Total & 40 & 24 & 2 & 6 & 8 \\
\hline
\end{tabular}

${ }^{\mathrm{z}}$ See Table 1 . counted according to the method for stigmatic pollination.

\section{RESULTS}

Sufficient pollen germination at the stigma and penetration into the style were observed in all the individuals (data not shown). Self pollen tubes were observed at the base of the styles in 18 individuals of the total (45\%) (Fig. 1), and 16 of them (40\%) succeeded to set seeds (Table 2). Selfed seeds were obtained in all the individuals of SC populations (AM and TO), while most of the individuals of mixed populations (YR, IK, IS and IR) failed to set selfed seeds. The arrested positions of the self pollen tubes in the style of the individuals that failed to set selfed seeds varied among individuals (Fig. 1).

Half of the individuals from SC populations (AM and TO) produced $>100$ selfed seeds, but some individuals in the mixed populations (YR, IK and IR) also produced

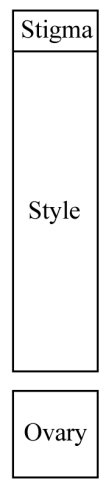

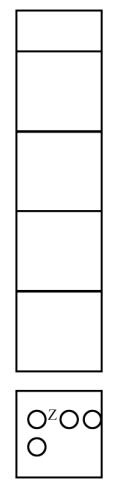

$\mathrm{AM}$

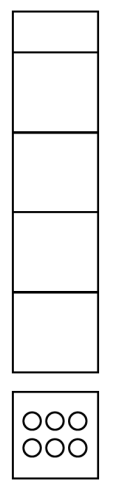

TO

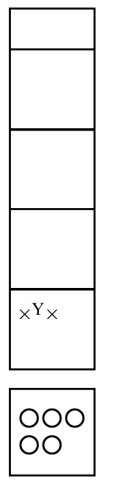

YR

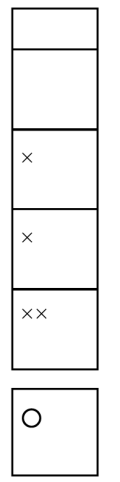

IK

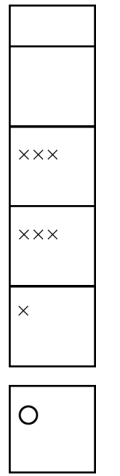

IS

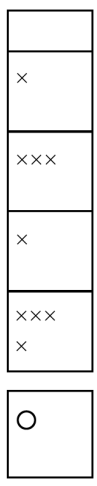

IR $\mathrm{x}$ See Table 1.

$\mathrm{Y}$ The arrested position of self pollen tube

$\mathrm{Z}$ The arrest of all self pollen tubes was not observed at the base of the style

Fig. 1. The arrested positions of self pollen tubes in L. longiflorum styles.

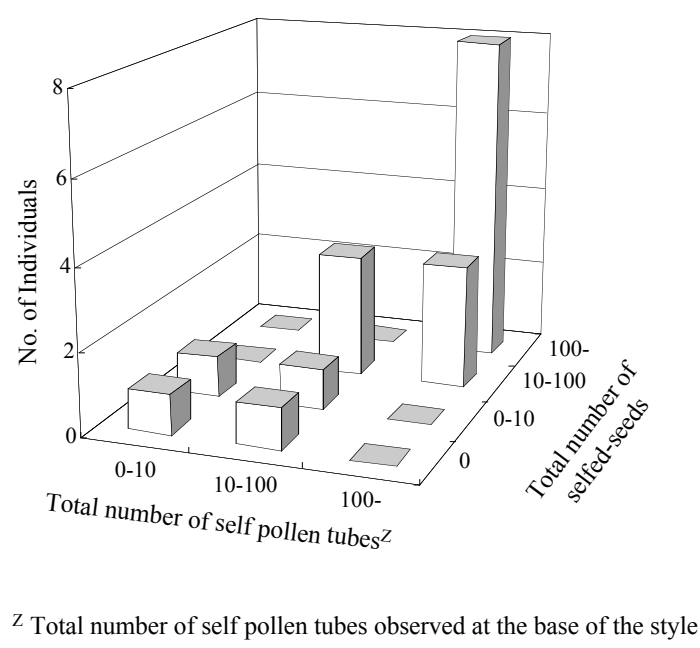

Fig. 2. Relationship between total number of selfed seeds and total number of self pollen tubes observed at the base of each style in L. longiflorum. 
$>100$ selfed seeds (Table 2 ). Pollen tubes reached the base of the styles in five individuals of YR population, but there was only one individual that produced over 100 selfed seeds. Total number of pollen tubes that were observed at the base of the styles tended to correspond to that of selfed seeds (Fig. 2). Pollen tubes often pro-

Table 3. Number of individuals to selfed seed set for cut-style pollination in self-incompatible L. longiflorum individuals

\begin{tabular}{ccc}
\hline Population $^{Z}$ & $\begin{array}{c}\text { Number of } \\
\text { individuals } \\
\text { examined }\end{array}$ & $\begin{array}{c}\text { Number of } \\
\text { individuals that set } \\
\text { selfed seeds (\%) }\end{array}$ \\
YR & 4 & $4(100)$ \\
IK & 2 & $2(100)$ \\
IS & 6 & $5(83.3)$ \\
IR & 6 & $6(100)$ \\
Total & 18 & $17(94.4)$ \\
\hline
\end{tabular}

${ }^{\mathrm{z}}$ See Table 1 .

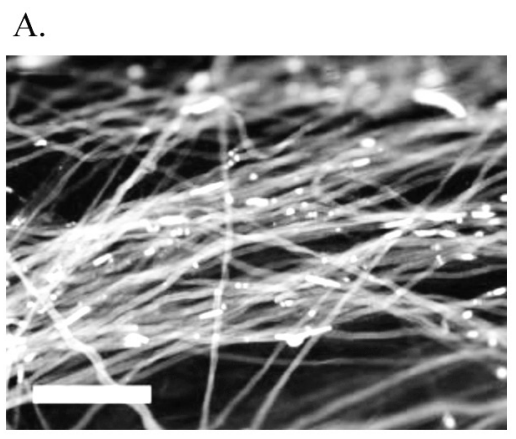

B.

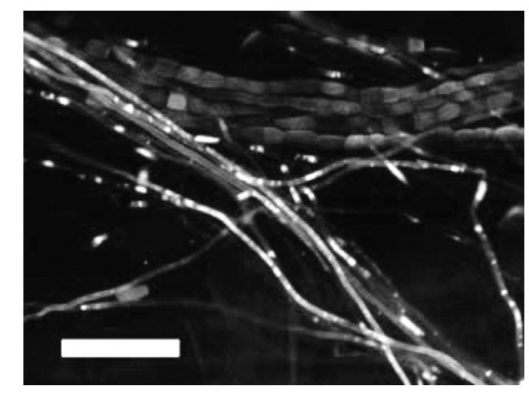

C.

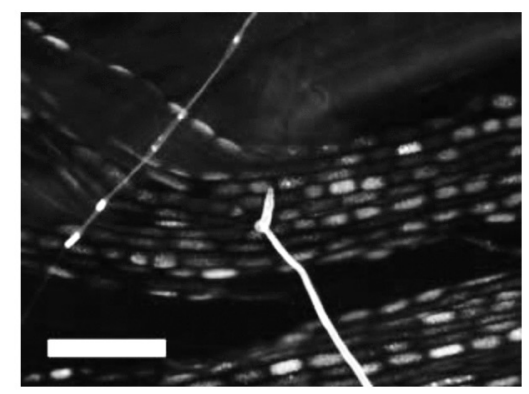

Fig. 3. Self pollen tubes of L. longiflorum in the style. A; Normal pollen tubes, B; Pollen tubes producing abnormal callose plugs, C; Abnormal pollen tube tip. Bars indicate $0.2 \mathrm{~mm}$. duced irregular callose plugs and showed abnormal morphology (Fig. 3. B and C) in the individuals that failed to set selfed seeds or produced only a small amount of selfed seeds.

Most of self-incompatible individuals (94.4\%) succeeded to set capsules and seeds in cut-style pollination (Table 3). The total seed number varied from 2 (IK) to 66 (IS) (data not shown).

\section{DISCUSSION}

The result that the self pollen tubes were arrested in the style of the individuals which failed to set selfed seeds (Fig. 1) agrees with the previous data obtained with the cultivars considered to be self-incompatible (Brierley et al., 1936). Total number of pollen tubes observed at the base of the style tended to correspond to that of selfed seeds (Fig. 2). It suggests that the decrease in selfed seed number in L. longiflorum is caused mainly by selfincompatibility but not by early-acting inbreeding depression. There were morphologically abnormal pollen tubes in the styles of the individuals that reduced the total seed number in self-pollination (Fig. 3). This result indicates that the growth of the most pollen tubes are inhibited by self-incompatibility response, but some pollen tubes are allowed to penetrate into the ovary for successful fertilization in the predominant and weak self-incompatible individuals. Most of the self-incompatible individuals (94.4\%) produced selfed seeds in the cut-style pollination (Table 3). Occurrence of quantitative variation of self-incompatibility in L. longiflorum, therefore, might be reinforced due to its long style (about $10 \mathrm{~cm}$ ). Two of 18 individuals in which the self pollen tubes reached the base of the styles failed to set seeds. Further observations of fertilization and embryo development are necessary to clarify when the incompatibility response occurred in these individuals. For example, greater number of ovules in Narcissus triandrus ceased their development following self-pollination as compared to cross-pollination, which resulted in a reduction of available ovules (Sage et al., 1999).

The arrested position of incompatible pollen tubes varies among individuals (Fig. 1), and Amaki et al. (1989) also confirmed the similar phenomenon in the cultivars of L. longiflorum 'Hinomoto' and 'Georgia'. Zhang and Hiratsuka (1999) reproted that the strength to inhibit the growth of self pollen tubes in the styles varies among cultivars of Japanese pear, and suggested that self-incompatibility may occur in different parts of the style among pollination combinations. Flowers of L. longiflorum have a hollow style with secretory cells, and nutrients from stylar exudate are utilized for pollen tube elongation (Kroh et al., 1970). It is suggested in L. longiflorum that the amount of the exudate varies among individuals, and it results in the variation of arrested positions of self pollen tubes in self-incompatible individuals. Ichimura and Yamamoto (1992) observed that self pollen tube elongation was promoted when the stylar exudate was injected into a stylar canal of self-incompatible $L$. longiflorum 'Hinomoto', and suggested that self-incompatibility results 
from the insufficient supply of stylar exudate.

Both genetic and biochemical mechanisms of selfincompatibility in L. longiflorum have not been identified, and it is unknown whether the arrested positions of self pollen tubes in self-incompatible individuals and the variation of selfed seeds number in the individuals are the results of the difference of S-allele or other factors. Mena-Ali and Stephenson (2007) found in Solanum carolinense that specific S-allele significantly sets more selfed seeds than other S-alleles. Identification of S-genotype for each individual and S-genotype segregation analysis among individuals showing different degrees of self-incompatibility is necessary to clarify the mechanism controlling the variation of self-incompatibility in L. longiflorum.

\section{REFERENCES}

Amaki, W., T. Tezuka and Y. Yamamoto 1989 Effect of pistillary sap on the in vivo pollen tube growth and changes in components of stylar sap by pollination in Lilium longiflorum Thunb. J. Japan. Soc. Hort. Sci., 57: 648-654

Ascher, P. D. and S. J. Peloquin 1968 Pollen tube growth and incompatibility following intra- and inter-specific pollinations in Lilium longiflorum. Amer. J. Bot., 55: 1230-1234

Brierley, P., S. L. Emsweller and J. C. Miller 1936 Easter lily breeding: Compatibilities in Lilium longiflorum Stocks. Proc. Amer. Soc. Hort. Sci., 34: 603-606

Brink, R. A. and D. C. Cooper 1939 Somatoplastic sterility in Medicago sativa. Science, 90: 545-546

Charlesworth, D. and B. Charlesworth 1987 Inbreeding depression and its evolutionary consequences. Ann. Rev. Ecol. Syst., 18: 237-268

de Nettancourt, D. 1977 Incompatibility in Angiosperms. Springer, Berlin, Heidelberg

Harder, L. D. and S. C. H. Barrett 2006 Ecology and evolution offlowers. Oxford University Press, New York

Hiscock, S. J. and S. M. Mclnnis 2003 The diversity of selfincompatibility systems in flowering plants. Plant Biol., 5: $23-32$

Ichimura, K. and Y. Yamamoto 1992 Changes in the amount and composition of stylar canal exudate after self- or crosspollination in self-incompatible Lilium longiflorum Thunb. J. Japan. Soc. Hort. Sci., 61: 609-617
Kroh, M., H. Miki-Hirosige, W. Rosen and F. Loewus 1970 Incorporation of label into pollen tube walls from myoinositol-labeled Lilium longiflorum pistils. Plant Physiol., 45: 92-94

Li, T. H. and Y. Niimi 1995 A comparison of seed sets in self-, intraspecific and interspecific pollination of Lilium species by stigmatic and cut-style pollination methods. J. Japan. Soc. Hort. Sci., 64: 149-159 (In Japanese with English summary)

Lloyd, D. G. 1968 Pollen tube growth and seed set in selfincompatible and self-compatible Leavenworthia (Crucifera) populations. New Phytol., 67: 179-195

Manicacci, D. and S. C. H. Barrett 1996 Fertility differences among floral morphs following selfing in tristylous Eichhornia paniculata (Pontederiaceae): Inbreeding depression or partial incompatibility. Amer. J. Bot., 83: 594-603

Mena-Ali, J. I and A. G. Stephenson 2007 Segregation analysis of partial self-incompatibility in self and cross progeny of Solanum carolinense reveal a leaky S-allele. Genetics, 177: $501-510$

Rigney, L. P. 1995 Postfertilization caused of differential success of pollen donors in Erythronium grandiflorum (Liliaceae): Nonrandom ovule abortion. Amer. J. Bot., 82 578-584

Sage, T. L., F. Strumas, W. W. Cole and S. C. H. Barrett 1999 Differential ovule development following self- and crosspollination: The basis of self-sterility in Narcissus triandrus (Amaryllidaceae). Amer. J. Bot., 86: 855-870

Sage, T. L. and F. B. Sampson 2003 Evidence for ovarian selfincompatibility as a cause of self-sterility in the relictual woody angiosperm, Pseudowintera axillaris (Winteraceae). Ann. Bot., 91: 807-816

Sakazono, S., M. Hiramatsu and H. Okubo 2008 Quantitative self-incompatibility and multiple origins of self-compatible populations in Lilium longiflorum Thunb. Book of Abstracts, 10th International Symposium on Flower Bulbs and Herbaceous Perennials, 10: 29 (Abstract)

Shimizu, M. 1971. The lilies of Japan. Seibundo-sinkosha Co. Ltd., Tokyo (In Japanese)

Stephenson, A. G., S. E. Travers, J. I. Mena-Ali and J. A. Winsor 2003 Pollen performance before and during the autotrophicheterotrophic transition of pollen tube growth. Phil. Trans. R. Soc. Lond. B, 358: 1009-1018

Zhang, S. L. and S. Hiratsuka 1999 Analysis of varietal differences in self- and cross-incompatibility reactions of Japanese pears using stylar culture technique. J. Japan. Soc. Hort. Sci., 68: 373- 383 (In Japanese with English summary) 